\title{
Modelling Fungal Growth, Mycotoxin Production and Release in Grana Cheese
}

\author{
Marco Camardo Leggieri ${ }^{1}\left(\mathbb{D}\right.$, Amedeo Pietri $^{2}$ and Paola Battilani ${ }^{1, *(\mathbb{C}}$ \\ 1 Department of Sustinable Crop Production, Università Cattolica del Sacro Cuore, Via E. Parmense, 84, \\ 29122 Piacenza, Italy; marco.camardoleggieri@unicatt.it \\ 2 Department of Animal Science, Food and Nutrition, Università Cattolica del Sacro Cuore, Via E. Parmense, \\ 84, 29122 Piacenza, Italy; amedeo.pietri@unicatt.it \\ * Correspondence: paola.battilani@unicatt.it; Tel.: +39-0523-599-254
}

Received: 29 November 2019; Accepted: 31 December 2019; Published: 2 January 2020

check for updates

\begin{abstract}
No information is available in the literature about the influence of temperature $(T)$ on Penicillium and Aspergillus spp. growth and mycotoxin production on cheese rinds. The aim of this work was to: (i) study fungal ecology on cheese in terms of T requirements, focusing on the partitioning of mycotoxins between the rind and mycelium; and (ii) validate predictive models previously developed by in vitro trials. Grana cheese rind blocks were inoculated with $A$. versicolor, P. crustosum, P. nordicum, P. roqueforti, and P. verrucosum, incubated at different T regimes $\left(10-30^{\circ} \mathrm{C}\right.$, step $5^{\circ} \mathrm{C}$ ) and after 14 days the production of mycotoxins (ochratoxin A (OTA); sterigmatocystin (STC); roquefortine C (ROQ-C), mycophenolic acid (MPA), Pr toxin (PR-Tox), citrinin (CIT), cyclopiazonic acid (CPA)) was quantified. All the fungi grew optimally around $15-25^{\circ} \mathrm{C}$ and produced the expected mycotoxins (except MPA, Pr-Tox, and CIT). The majority of the mycotoxins produced remained in the mycelium ( $\sim 90 \%$ ) in three out of five fungal species (P. crustosum, P. nordicum, and P. roqueforti); the opposite occurred for A. versicolor and P. verrucosum with $71 \%$ and $58 \%$ of STC and OTA detected in cheese rind, respectively. Available predictive models fitted fungal growth on the cheese rind well, but validation was not possible for mycotoxins because they were produced in a very narrow $\mathrm{T}$ range.
\end{abstract}

Keywords: ochratoxin A; sterigmatocystin; Penicillium; Aspergillus versicolor; temperature; ecology; modelling; partitioning

\section{Introduction}

Grana cheese is a traditional Italian hard cheese, obtained from unpasteurized cow's milk, aged for a minimum period of nine months up to four years. This type of cheese is of great importance for Italy's food culture and economy; two brands of grana cheese, "Grana Padano" and "Parmigiano Reggiano," are recognized with the Protected Designation of Origin certificate (PDO). Grana cheeses are high-quality manufactured products; after a 9-month storage period, the $a_{w}$ varies between 0.92 and 0.85 on the rind and between 0.94 and 0.87 if a thicker layer is considered; the relative humidity of storehouses ranges between $72 \%$ and $88 \%$ [1]. As defined in the guidelines of many PDO products, the ripening of hard cheese is carried out normally in a $\mathrm{T}$ range from $10-20^{\circ} \mathrm{C}$. For Italian grana cheese, the environmental conditions during aging are between 15 and $22^{\circ} \mathrm{C}$, as described in "Parmigiano Reggiano" and "Grana Padano" cheese production guidelines [2].

The development of filamentous fungi in grana cheese during ripening, limited to the rind surface, is common and accepted; in fact, growth of mold may be beneficial for the development of the characteristic flavor and aroma of dairy products, due to mold involvement with the degradation of lipids and protein. In addition, the surface microbiota can have a protective role against pathogenic spoilage microorganisms [3]. 
However, fungi belonging to Aspergillus, Penicillium, and Mucor spp. can cause cheese spoilage [4,5] with many undesired and adverse health effects, such as mycotoxin contamination. Therefore, during the ripening period, the cheese wheels are brushed at fixed times, to remove developing molds; further, the wheels are carefully brushed or washed before sale.

Globally, several studies have focused on the occurrence of mycotoxins in cheese; the most widely reported compounds were citrinin (CIT), penitrem A (PA), roquefortine C (ROQ-C), sterigmatocystin (STC), and ochratoxin A (OTA) [6-11]. Penicillium spp. is reported as the dominant fungal genus growing on cheese [4]. Information about penicillia growing on grana cheese during ripening has been reported by Decontardi et al. $[10,12]$. In particular, P. crustosum and P. solitum were the dominant species isolated, but other mycotoxin producing fungi identified were A. flavus and P. verrucosum. OTA was detected in all the cheese samples analyzed [10].

Although mycotoxin contamination may pose an important risk for consumer health and global trade [13], few studies have addressed the problem; therefore, the influence of ecological factors during cheese manufacturing and ripening on mycotoxin contamination has scarcely been investigated. The relevance of ecology in determining the dominant and/or the co-occurring contaminants has been stressed by several studies; therefore, mycotoxin prevalence is expected to be extremely variable in cheese ripening, depending on the storage conditions. A predictive model, accounting for the fungal infection cycle, is considered imperative to predict how ecological factors, such as temperature (T) and water activity $\left(a_{w}\right)$, affect fungal occurrence and mycotoxin contamination in matrices. So far, only limited attempts have been made to model the in vitro sporulation [14], growth, and mycotoxin production [1] of some mycotoxigenic fungi reported in grana cheese. Data on the impact of ecology on each step of the infection cycle are fundamental in order to develop predictive models for the risk of mycotoxin contamination during grana cheese ripening as a valuable support in risk assessments and management.

The aim of this study was to investigate: (i) the effect of $\mathrm{T}$ on growth and mycotoxin production by $A$. versicolor, P. crustosum, P. nordicum, P. roqueforti, and P. verrucosum artificially inoculated on grana cheese rind blocks; (ii) the partitioning of mycotoxins between the cheese rind and fungal mycelium; and (iii) the reliability of growth and mycotoxin production models, previously developed using data collected in in vitro trials with fungi inoculated on artificial media.

\section{Materials and Methods}

\subsection{Cheese Blocks Sampling and Disinfection}

Squared cheese rind blocks (Consorzio per la tutela del Formaggio Grana Padano, Lodi, Italy and Consorzio del Formaggio Parmigiano Reggiano, Reggio Emilia, Italy) of about $4 \times 4 \times 2 \mathrm{~cm}$ (approximate weight: $40 \mathrm{~g}$ ) were collected from the flat, upper part of 12-month old ripening grana cheese wheels, vacuum-packed in special plastic bags and stored at $5{ }^{\circ} \mathrm{C}$ until use. The water activity $\left(a_{w}\right)$ of the matrix was measured using an Aqualab LITE device (version 1.3 C Decagon devices Inc., Pullman, WA, USA).

The cheese rind blocks were disinfected as described by Battilani et al. [15] with minor changes, and all operations were performed under a sterile hood. In brief, the cheese blocks were washed in a $2 \%$ solution of $\mathrm{NaClO}$ (Carlo Erba, Milan, Italy) for two minutes, washed in absolute ethanol for two minutes and dried for about five minutes, and passed over a Bunsen burner flame three times for $2 \mathrm{~s}$.

\subsection{Inoculum Preparation, Inoculation, and Incubation of the Cheese Blocks}

Ingredients for media were purchased from Himedia Laboratories (Mumbai, India). Fungal strains of five mycotoxin producing fungi originating from various official fungal collections (Table 1) were centrally inoculated on $60 \mathrm{~mm}$ diameter plates filled with Malt Extract Agar (MEA [16]) and incubated in the dark at $25^{\circ} \mathrm{C}$ for seven days. 
Table 1. Fungal strains used in this study, with the country, matrix of isolation, and mycotoxins reported in literature for these fungal species.

\begin{tabular}{|c|c|c|c|c|}
\hline Species & Strain Code ${ }^{a}$ & $\begin{array}{l}\text { Country of } \\
\text { Isolation }\end{array}$ & Matrix of Isolation & Mycotoxin \\
\hline A. versicolor $\mathrm{b}$ & CBS 108959 & Denmark & & Sterigmatocystin (STC) \\
\hline P. crustosum & CBS 115503 & The Netherlands & & $\begin{array}{c}\text { Penitrem A (PA) } \\
\text { Roquefortine C (ROQ-C) }\end{array}$ \\
\hline P. nordicum & BFE 856 & Italy & Ham & $\begin{array}{c}\text { Ochratoxin A (OTA) } \\
\text { Roquefortine C (ROQ-C) }\end{array}$ \\
\hline P. roqueforti & CBS 221.30 & USA & & $\begin{array}{c}\text { Mycophenolic acid (MPA) } \\
\text { Pr-Toxin (PR-Tox) }\end{array}$ \\
\hline P. verrucosum & MUM 16.76 & Italy & Cheese & $\begin{array}{l}\text { Ochratoxin A (OTA) } \\
\text { Citrinin (CIT) }\end{array}$ \\
\hline
\end{tabular}

\footnotetext{
${ }^{a}$ CBS: Westerdijk Fungal Biodiversity Institute; MUM: Micoteca da Universidade do Minho; BFE: Federal Research Centre for Nutrition and Food. ${ }^{b}$ A. versicolor CBS 108959 was later identified as A. jensenii by Decontardi et al. [12] but $A$. versicolor will be kept in the text to remain consistent with the CBS website database labelling.
}

Fungi inoculation was performed using the 7-day old colonies. For each fungal strain, a small amount of mycelium and spores was collected using a sterile metal needle and centrally laid on the external surface of the cheese blocks. The trial was managed in triplicates [15]. The amount of inoculum was quantified by picking a similar quantity of fungal material used as inoculum, with $1 \mathrm{~mL}$ of bidistilled water added and counting the number of spores using a haemocytometer. The inoculum concentration assessment was repeated 3 times for each fungal isolate.

Humid chambers were prepared using round glass cups (diameter: $19 \mathrm{~cm}$; height: $9 \mathrm{~cm}$; approximate volume: $2.350 \mathrm{~L}$ ) with $100 \mathrm{~mL}$ of a sterilized $\mathrm{NaCl}$ (Carlo Erba, Milan, Italy) solution added, prepared as described by Dallyn and Fox [17] to obtain $0.93 a_{w}$. A properly shaped metal grid was sterilized and placed inside the cups. The inoculated cheese blocks were then put on the grid to avoid any contact with the salt solution [18]. All the cups were then sealed with a plastic film and incubated at temperatures (T) ranging from 10 to $30^{\circ} \mathrm{C}\left(5^{\circ} \mathrm{C}\right.$ step) with a $12 \mathrm{~h}$ photoperiod for 21 days.

\subsection{Data Collection}

Fungal growth: at the end of incubation, two perpendicular diameters of the fungal colony (mm) were measured. Then, the colonies were removed, by gently scraping the mycelium from the cheese surface, and put in a Falcon ${ }^{\circledR}$ plastic vial with a screw cap. Both the Falcon vials and the cheese blocks were stored at $-20^{\circ} \mathrm{C}$ until use.

Mycotoxin Analysis: the chemicals and solvents used for the extraction and clean-up solutions were ACS grade or equivalent (Carlo Erba, Milan, Italy), mycotoxin standards were obtained from Sigma-Aldrich (St. Louis, MO, USA). Mycotoxin analyses were performed separately both on the mycelium colonies and the cheese blocks. Rind cheese and fungal mycelium were ground and homogenised before analysis. All samples were subdivided for consistency in three aliquots for mycotoxin extraction using $\mathrm{CH}_{3} \mathrm{CN}: \mathrm{H}_{2} \mathrm{O}(80: 20 \mathrm{v} / v)$ for MPA, PR-toxin, ROQ-C, STC and PA, $\mathrm{CH}_{3} \mathrm{CN}: 10 \mathrm{mM} \mathrm{H}_{3} \mathrm{PO}_{4}(70: 30 \mathrm{v} / \mathrm{v})$ for CIT and $\mathrm{CH}_{3} \mathrm{OH}: 3 \% \mathrm{NaHCO}_{3}(50: 50 \mathrm{v} / \mathrm{v})$ for OTA. Toxin analyses were performed by HPLC-MS/MS (Thermo-Fisher Scientific, San Jose, CA, USA) and standards for STC, CIT, ROQ, MPA, OTA, PR toxin, and PA were prepared, as described by Camardo Leggieri et al. [1]. Data were reported as total ng of mycotoxin on cheese block or mycelium. Limits of detection (LODs) were $1 \mathrm{ng}$ for ROQ-C, $5 \mathrm{ng}$ for MPA, PA, STC, OTA, and CIT, $10 \mathrm{ng}$ for PR-toxin.

\subsection{Data Analysis}

Statistical analyses were performed using SPSS v.25 (SPSS Inc., Armonk, NY, USA, 2012) software. Mycotoxin production data were $\ln$ transformed to homogenize the variance and tested for normality 
using the Shapiro-Wilk test. As all data succeeded the normality test, the one way-ANOVA was applied. The Tukey test was applied to highlight significant differences between means.

Modelling of growth data: data of fungal growth on natural substrate, intended as the diameter of fungal colonies grown on cheese rind, at different $T$ regimes, were rated on the maximum value observed to obtain the relative growth on a $0-1$ scale $(0=$ no growth; $1=$ maximum growth). Then, fungal relative growth on the cheese rind was fitted to the models published by Camardo Leggieri et al. [1]. Briefly, Bete function [19] and a logistic function described in vitro fungal growth on artificial medium (Czapeck Yeast Agar (CYA)) under different $\mathrm{T}$ and $a_{w}$ regimes, respectively. Residuals were calculated as the mathematical difference between relative growth collected on natural substrate and the function. Positive values for the residuals (on the y-axis) mean the prediction was overestimated, negative values mean the prediction was underestimated and 0 means the estimation was correct.

\section{Results}

The fungal inoculum concentration, measured on three replicates prepared for each fungus, was $\sim 10^{5}$ spore/mL; therefore, this was assumed as the number of spores distributed on each cheese block.

\subsection{Fungal Growth}

Almost all fungi included in the study grew in the $\mathrm{T}$ range considered $\left(10-30^{\circ} \mathrm{C}\right)$. A. versicolor and $P$. roqueforti did not grow at $10^{\circ} \mathrm{C}$ while P. nordicum and P. roqueforti did not grow at $30^{\circ} \mathrm{C}$; for these aforementioned combinations fungus $\times$ temperature, at the end of incubation the diameter of the fungal colony was comparable to the initial inoculum. Therefore, no measurable growth was assumed for $A$. versicolor and P. roqueforti at $10^{\circ} \mathrm{C}$ and for $P$. nordicum and $P$. roqueforti at $30^{\circ} \mathrm{C}$.

All the $\mathrm{T}$ regimes tested significantly affected mean fungal growth $(p \leq 0.01)$, with maximum colony diameter at $20^{\circ} \mathrm{C}$ and minimum at 10 and $30^{\circ} \mathrm{C}$ (Table 2). Significant differences between the two fungal genera included in the study were detected, with 8.5 versus $13.5 \mathrm{~mm}$ mean colony diameter, respectively, for A. versicolor and Penicillium spp. (Table 2). Almost all the fungal colonies showed the production of spores after 10 days of incubation; colonies of P. verrucosum are shown in Figure 1, as an example.

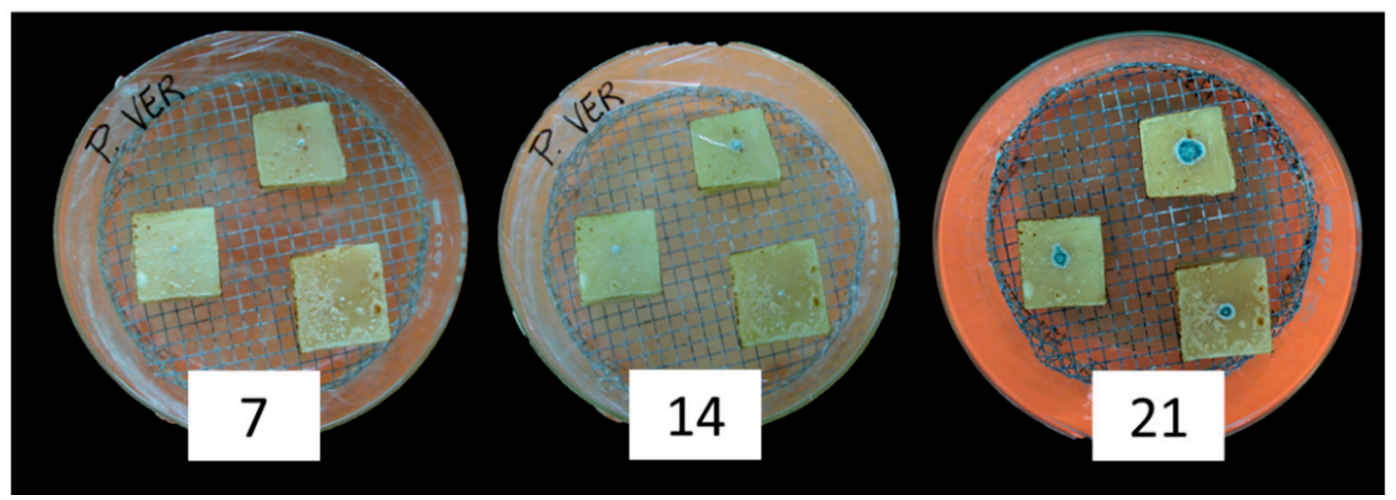

Figure 1. Growth of Penicillium verrucosum inoculated on cheese blocks (triplicate) after 7, 14, and 21 days of incubation at $25^{\circ} \mathrm{C}$ with 0.93 water activity $\left(a_{w}\right)$. 
Table 2. Analysis of variance (ANOVA) for fungal growth (colony diameter; $\mathrm{mm}$ after 21 days of incubation) in different regimes of temperature $\left(10-30{ }^{\circ} \mathrm{C}\right.$, step $\left.5^{\circ} \mathrm{C}\right)$ and for diverse fungi (Aspergillus versicolor, Penicillium crustosum, P. nordicum, P. roqueforti, and P. verrucosum). Standard deviation of growth was reported in parenthesis.

\begin{tabular}{ccc}
\hline Factors & \multicolumn{3}{c}{ Growth } \\
\hline Temperature $\left({ }^{\circ} \mathbf{C}\right)$ (A) & $* *$ & $d \S$ \\
10 & 3.4 & $c$ \\
15 & 11.5 & $a$ \\
20 & 22.1 & $b$ \\
25 & 16.3 & $d$ \\
30 & 3.1 & \\
Fungi (B) & $* *$ & $b$ \\
A. versicolor & 8.5 & $a$ \\
P. crustosum & 13.1 & $a$ \\
P. nordicum & 13.4 & $a$ \\
P. roqueforti & 13.3 & $a$ \\
P. verrucosum & 14.1 & \\
(A $\times$ B) & $* *$ & \\
\hline \$ Different letters define significant difference according to the Tukey test; ${ }^{* *} p \leq 0.01$.
\end{tabular}

The interaction between $\mathrm{T}$ and fungal species was significant $(p \leq 0.01)$. A. versicolor and P. crustosum showed optimal growth at 25 and $20^{\circ} \mathrm{C}$, respectively; both P. nordicum, and P. verrucosum grew optimally at 15 and $20^{\circ} \mathrm{C}$, while $P$. roqueforti at 20 and $25^{\circ} \mathrm{C}$ (Figure 2).

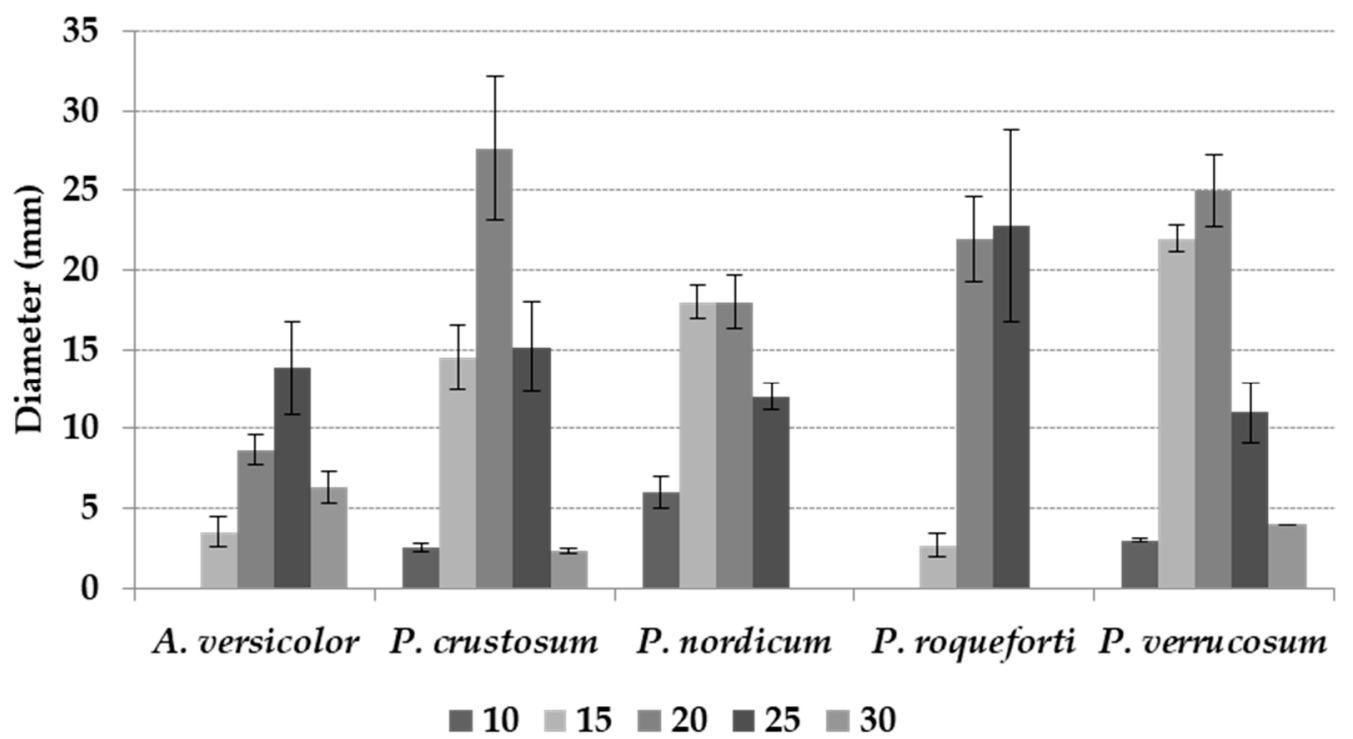

Figure 2. Mean colony diameter ( $\mathrm{mm}$ ) after 21 days of incubation of Aspergillus versicolor, Penicillium crustosum, $P$. nordicum, $P$. roqueforti, and P. verrucosum at different temperatures $(\mathrm{T})$ of incubation $\left(10-30{ }^{\circ} \mathrm{C}, 5{ }^{\circ} \mathrm{C}\right.$ step). The bars indicate the mean standard error.

Fungal growth was commonly very limited in the marginal $\mathrm{T}$ regimes studied. In the respective optimal T regime, after 21 days of incubation (Figure 2), P. crustosum reached the largest colony diameter (28 mm), followed by P. verrucosum $(25 \mathrm{~mm})$, P. roqueforti $(23 \mathrm{~mm})$, and P. nordicum and A. versicolor (about $14 \mathrm{~mm}$ each). Colony diameters in detail for every species are reported in Table 2. 


\subsection{Mycotoxin Producion}

All the toxins reported in the literature for the studied fungi were detected, with the exception of MPA, Pr-Tox, and CIT, produced by P. roqueforti and P. verrucosum, respectively; these toxins were always below the LOD (Figure 3).

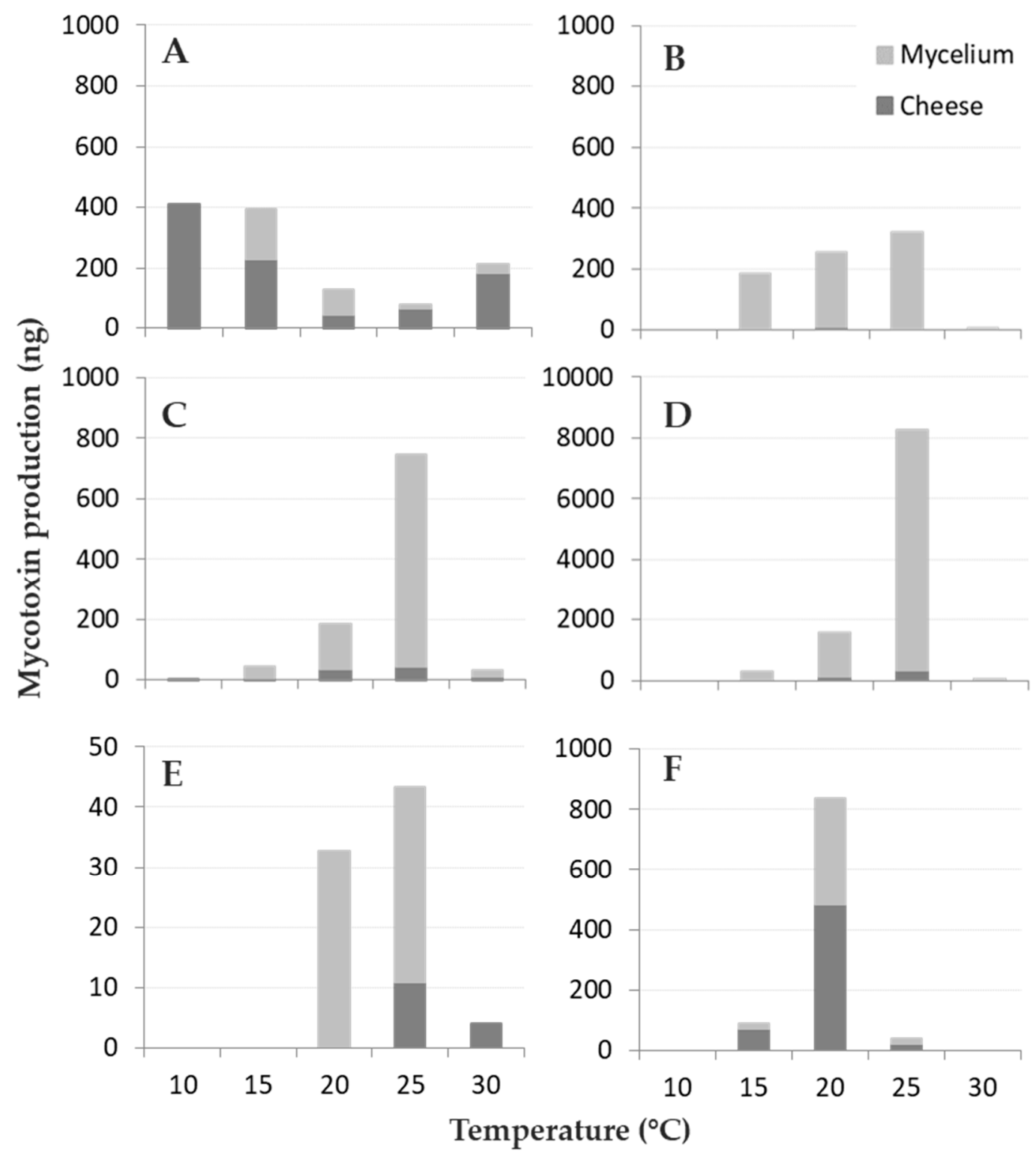

Figure 3. Mycotoxin (ng) partitioning between cheese rind and fungal mycelium for the fungi considered at different temperature levels $\left(10-30{ }^{\circ} \mathrm{C}\right.$, step $\left.5{ }^{\circ} \mathrm{C}\right)$ : (A) sterigmatocystin (STC)-Aspergillus versicolor, (B) penitrem A (PA)-Penicillium crustosum, (C) roquefortine C (ROQ-C)-P. roqueforti, (D) ROQ-C-P. crustosum (E) ochratoxin A (OTA)-P. nordicum and (F) OTA-P. verrucosum. The amount of mycotoxin detected in cheese rind is reported in dark grey, while the pale grey part of the bars represents the number of mycotoxins detected in fungal mycelium.

The ANOVA was applied to all the data on mycotoxins produced after 21 days of incubation on the cheese blocks, adding up the toxins detected in the fungal colony and on the cheese blocks (Table 3). $\mathrm{T}$ had a significant impact on all the mycotoxins analysed, as with the considered partitioning (rind and colony). The interaction " $\mathrm{T}$ " $\times$ "Partitioning" resulted significant only for PA and OTA produced by P. crustosum and P. nordicum, respectively (Table 3). 
Table 3. Analysis of variance (ANOVA) for mycotoxin production (ng) in different regimes of temperature $\left(10-30{ }^{\circ} \mathrm{C}\right.$, step $\left.5{ }^{\circ} \mathrm{C}\right)$ and for different partitioning (cheese rind or mycelium). Standard deviation of mycotoxin were reported in parenthesis.

\begin{tabular}{|c|c|c|c|c|c|c|c|c|c|c|c|c|}
\hline \multirow{2}{*}{ Factors } & \multirow{2}{*}{\multicolumn{2}{|c|}{$\begin{array}{c}\text { A. versicolor } \\
\text { STC }\end{array}$}} & \multicolumn{4}{|c|}{ P. crustosum } & \multirow{2}{*}{\multicolumn{2}{|c|}{$\begin{array}{c}\text { P. nordicum } \\
\text { OTA }\end{array}$}} & \multirow{2}{*}{\multicolumn{2}{|c|}{$\begin{array}{c}\text { P. roqueforti } \\
\text { ROQ-C }\end{array}$}} & \multirow{2}{*}{\multicolumn{2}{|c|}{$\begin{array}{c}\text { P. verrucosum } \\
\text { OTA }\end{array}$}} \\
\hline & & & \multicolumn{2}{|c|}{ PA } & \multicolumn{2}{|c|}{ ROQ-C } & & & & & & \\
\hline Temperature $\left({ }^{\circ} \mathrm{C}\right)(\mathrm{A})$ & \multicolumn{2}{|c|}{ ** } & \multicolumn{2}{|c|}{ ** } & \multicolumn{2}{|c|}{$* *$} & \multicolumn{2}{|c|}{$* *$} & \multicolumn{2}{|c|}{$* *$} & \multicolumn{2}{|c|}{ ** } \\
\hline 10 & $\begin{array}{c}409.3 \\
( \pm 1.84)\end{array}$ & $a^{\S}$ & $<\mathrm{LOD}$ & $\mathrm{b}$ & $<\mathrm{LOD}$ & c & $<\mathrm{LOD}$ & $\mathrm{c}$ & $\begin{array}{c}3.8 \\
( \pm 1.13)\end{array}$ & c & $<\mathrm{LOD}$ & c \\
\hline 15 & $\begin{array}{c}197.3 \\
( \pm 1.60)\end{array}$ & $\mathrm{ab}$ & $\begin{array}{c}92.6 \\
( \pm 12.45)\end{array}$ & $\mathrm{a}$ & $\begin{array}{c}151.8 \\
( \pm 5.14)\end{array}$ & $\mathrm{b}$ & $<$ LOD & $\mathrm{c}$ & $\begin{array}{c}19.4 \\
( \pm 2.03)\end{array}$ & $\mathrm{bc}$ & $\begin{array}{c}43.2 \\
( \pm 2.93)\end{array}$ & $\mathrm{b}$ \\
\hline 20 & $\begin{array}{c}64 \\
( \pm 2.25)\end{array}$ & $\mathrm{bc}$ & $\begin{array}{c}125.4 \\
( \pm 8.21)\end{array}$ & $\mathrm{a}$ & $\begin{array}{c}787.4 \\
( \pm 3.75)\end{array}$ & $\mathrm{a}$ & $\begin{array}{c}16.4 \\
( \pm 5.63)\end{array}$ & $\mathrm{ab}$ & $\begin{array}{c}91.7 \\
( \pm 2.48)\end{array}$ & $\mathrm{ab}$ & $\begin{array}{c}418.6 \\
( \pm 2.63)\end{array}$ & a \\
\hline 25 & $\begin{array}{c}38.8 \\
( \pm 2.96)\end{array}$ & $\mathrm{bc}$ & $\begin{array}{c}160 \\
( \pm 14.71)\end{array}$ & $\mathrm{a}$ & $\begin{array}{l}4140.5 \\
( \pm 5.63)\end{array}$ & $\mathrm{a}$ & $\begin{array}{c}21.6 \\
( \pm 3.75)\end{array}$ & $\mathrm{a}$ & $\begin{array}{c}370.5 \\
( \pm 5.19)\end{array}$ & $\mathrm{a}$ & $\begin{array}{c}12.4 \\
( \pm 4.49)\end{array}$ & $\mathrm{bc}$ \\
\hline 30 & $\begin{array}{c}122.2 \\
( \pm 2.67)\end{array}$ & c & $<\mathrm{LOD}$ & $\mathrm{b}$ & $\begin{array}{c}22.3 \\
( \pm 2.84)\end{array}$ & $\mathrm{b}$ & $\begin{array}{c}4.0 \\
( \pm 3.35)\end{array}$ & $\mathrm{bc}$ & $\begin{array}{c}14.7 \\
( \pm 1.73)\end{array}$ & c & $<\mathrm{LOD}$ & c \\
\hline Partitioning (B) & \multicolumn{2}{|c|}{$* *$} & \multicolumn{2}{|c|}{$* *$} & \multicolumn{2}{|c|}{$* *$} & \multicolumn{2}{|c|}{$(I 0.00) * *$} & \multicolumn{2}{|c|}{$* *$} & \multicolumn{2}{|c|}{ n.s. } \\
\hline Cheese rind & $\begin{array}{c}186.8 \\
( \pm 2.64)\end{array}$ & a & $\begin{array}{c}1.5 \\
( \pm 2.31)\end{array}$ & $\mathrm{b}$ & $\begin{array}{c}101.9 \\
( \pm 8.07)\end{array}$ & $\mathrm{b}$ & $\begin{array}{c}3.0 \\
( \pm 3.00)\end{array}$ & $\mathrm{b}$ & $\begin{array}{c}19.0 \\
( \pm 2.38)\end{array}$ & $\mathrm{b}$ & $\begin{array}{c}113.5 \\
( \pm 11.25)\end{array}$ & a \\
\hline Mycelium & $\begin{array}{c}76.1 \\
( \pm 3.39)\end{array}$ & $\mathrm{b}$ & $\begin{array}{c}204.4 \\
( \pm 6.02)\end{array}$ & $\mathrm{a}$ & $\begin{array}{c}2642 \\
( \pm 6.03)\end{array}$ & $\mathrm{a}$ & $\begin{array}{c}16.3 \\
( \pm 5.58)\end{array}$ & $\mathrm{a}$ & $\begin{array}{c}266.9 \\
( \pm 3.81)\end{array}$ & $\mathrm{a}$ & $\begin{array}{c}81.6 \\
( \pm 9.21)\end{array}$ & $\mathrm{b}$ \\
\hline $\mathbf{A} \times \mathbf{B}$ & n.s & & $* *$ & & n.s. & & $* *$ & & n.s. & & n.s. & \\
\hline
\end{tabular}

$\S$ Different letters define significant difference according to the Tukey test; n.s.: not significant; ${ }^{* *} p \leq 0.01$. 
All fungi produced their respective mycotoxins between 15 and $25^{\circ} \mathrm{C}$ (Table S1 and Table 3); in particular, A. versicolor and P. roqueforti produced mycotoxins in the whole T range tested $\left(10-30^{\circ} \mathrm{C}\right)$, while P. nordicum only at between 20 and $30^{\circ} \mathrm{C}$. At the lowest $\mathrm{T}$ tested $\left(10^{\circ} \mathrm{C}\right)$ only $A$. versicolor produced the highest amount of STC detected, while the minimum was measured after incubation at $25^{\circ} \mathrm{C}$. On the contrary, all the other fungi showed an opposite trend, with the optimal $\mathrm{T}$ for mycotoxin production at $20-25^{\circ} \mathrm{C}$, and $20^{\circ} \mathrm{C}$ for OTA production by P. verrucosum. Therefore, four out of five species followed a "bell-shaped" trend in producing their mycotoxins in different $\mathrm{T}$ regimes, $A$. versicolor showed a reverse bell, with a remarkable decrease in STC production at 20 and $25^{\circ} \mathrm{C}$ compared to 10 and $15^{\circ} \mathrm{C}$.

The interaction between $\mathrm{T}$ and partitioning between the cheese rinds and fungal mycelium is reported in Figure 3, even if not statistically significant. Mycotoxin contamination in cheese rind was generally limited: in three out of five fungal species (P. crustosum, P. nordicum, and P. roqueforti) the majority of the mycotoxins produced remained located in the fungal colony $(\sim 90 \%)$ while the opposite happened for A. versicolor and P. verrucosum (Figure 3A,F) with $71 \%$ and $58 \%$ of STC and OTA detected in cheese rind, respectively. For A. versicolor (Figure 3A), 85\% of STC was recovered in cheese rind at the highest $\mathrm{T}$ tested while the lowest $(34 \%)$ was detected at $20^{\circ} \mathrm{C}$. Regarding OTA, $81 \%$ was released in cheese by $P$. verrucosum at $15{ }^{\circ} \mathrm{C}$, around $55 \%-58 \%$ at 20 and $25^{\circ} \mathrm{C}$ (Figure $3 \mathrm{~F}$ ) and only $25 \%$ at $25{ }^{\circ} \mathrm{C}$ was released by $P$. nordicum in cheese.

\subsection{Modeling Fungal Growth}

Data on fungal relative growth on cheese rind obtained in this study were compared with modeled data of fungal growth in vitro at $0.93 a_{w}$ [1]. In Figure 4, plotted data of cheese rind (grey dots) vs. artificial medium (dashed lines) commonly followed a comparable trend.

Detailed information on the comparison between growth on cheese rind and the model built based on in vitro data are shown in Figure 5, where residuals were calculated. In particular, with the exception of P. verrucosum (Figure 4E), all the cheese rind data can be well-described by the functions developed with data collected in vitro, as points are close to the lines (Figure 4). Trends described by cheese rind data are narrower than the fungal relative growth models, in particular for $A$. versicolor, P. crustosum, and P. nordicum, nearly overlapping at the optimal T of $25^{\circ} \mathrm{C}$. For P. verrucosum (Figure $4 \mathrm{E}$ ) at $\mathrm{T}=15-20^{\circ} \mathrm{C}$, a higher fungal relative growth on cheese rind was observed compared to the model, which corresponds to an under-estimation of fungal growth on cheese rind by the fitting function and to a positive residue score (Figure 5). In general, with the exception of P. verrucosum, residues are close to 0 for optimal growth and for a broad range of $\mathrm{T}$. 


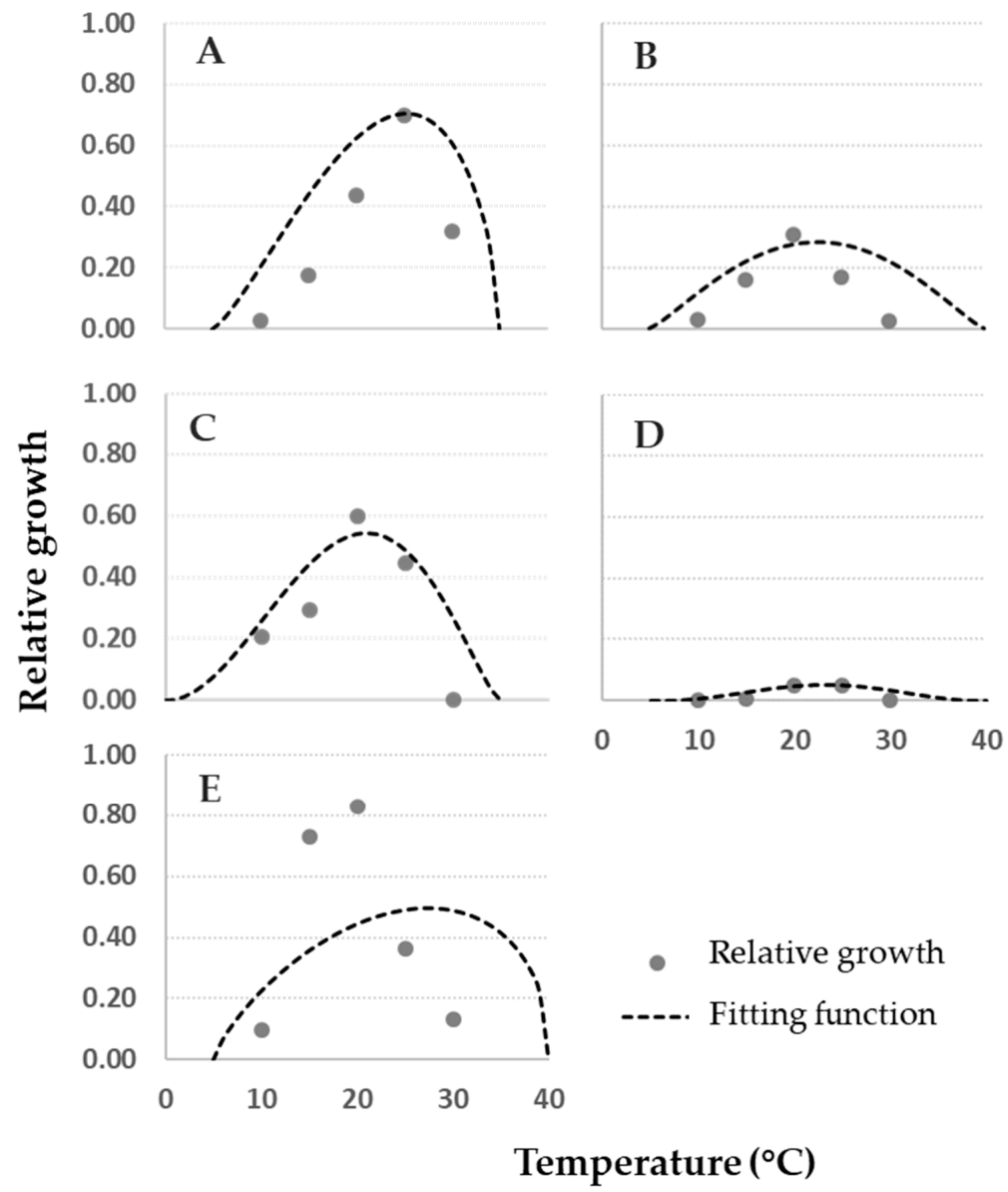

Figure 4. Data of fungal relative growth on cheese rind (grey dots) and the fitting functions based on relative growth data obtained on Czapeck Yeast Agar (dashed lines, [1]) for (A) Aspergillus versicolor, (B) Penicillium crustosum, (C) P. nordicum, (D) P. roqueforti, and (E) P. verrucosum at different temperature regimes $\left(0-40{ }^{\circ} \mathrm{C}\right.$, step $\left.5{ }^{\circ} \mathrm{C}\right)$.

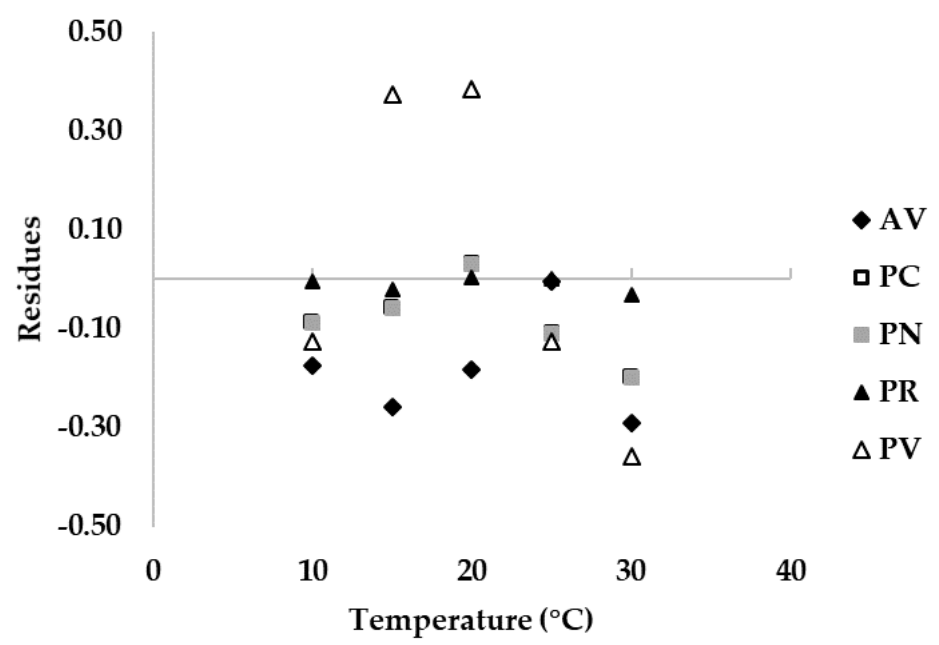

Figure 5. Plot of residuals between fungal relative growth on cheese rind and the fitting functions based on relative growth data obtained on Czapeck Yeast Agar, calculated for Aspergillus versicolor (AV), Penicillium crustosum (PC), P. nordicum (PN), P. roqueforti (PR), and P. verrucosum (PV) at different incubation temperatures $\left(0-40{ }^{\circ} \mathrm{C}\right.$, step $\left.5^{\circ} \mathrm{C}\right)$. 


\subsection{Modeling Mycotoxin Production}

As well as for fungal growth and for mycotoxin production, data on cheese rind obtained in this study were compared with modeled data of mycotoxin production in vitro [1]. In this study, toxins were produced on cheese in a very narrow range, with comparable amounts only in two T regimes and 10 times lower amounts both for lower or higher T. Therefore, it was not possible to fit data on previously developed functions, neither to develop new functions. The optimal $\mathrm{T}$ for toxin production has been confirmed for all fungi.

\section{Discussion}

The co-occurrence of toxigenic fungi on grana cheese, during ripening and storage $[5,10,20]$ is a matter of concern for manufacturers and consumers, because of the possible production of different mycotoxins. There is a complete lack of regulation for mycotoxins (with the exception of aflatoxin $\mathrm{M}_{1}$ arising from milk used for cheese production) in cheese. OTA has been reported in grated cheese [21] and is regulated for several commodities [22,23]. Despite the regulations in force, OTA has been reported in human plasma and breast milk [24-28], confirming human exposure to OTA, in particular of vulnerable groups of consumers such as infants.

All the mycotoxins considered in this study could theoretically co-occur in cheese. The co-occurrence of toxic compounds in feed and food is of increasing interest in the scientific community [29-31]. The knowledge available is still limited, but it suggests synergistic effects of mycotoxin mixtures, with an impact on consumer health possibly more severe compared to the addition of single mycotoxin effects [32,33].

Cheese consumption worldwide is an important component of human diets $[34,35]$ and it is therefore essential to understand the conditions that favor mycotoxin production and, possibly, to predict their occurrences.

Penicillium species are commonly reported as the dominant contaminant fungi in cheese [4] and of these P. roqueforti, P. crustosum [36], and P. citrinum are the most significant [37]. P. nordicum and its closely related species $P$. verrucosum are also signaled, even if more reported in ripened pork meat $[15,18,36]$. A. versicolor was also included because it has previously been reported as a cheese contaminant [4].

Almost all the fungi were able to grow on the real matrix cheese. Despite a few differences, the impact of $\mathrm{T}$ is consistent with previous reports, suggesting that the fungi included in this study grow readily between 15 and $25^{\circ} \mathrm{C}$ on different media culture [1,38,39]. A matrix effect was noticed for P. verrucosum; in fact, the fitting to the model developed with data collected on CYA did not fit perfectly, with growth enhanced on cheese at 15 and $20^{\circ} \mathrm{C}$. As for growth, also mycotoxin production is dependent on the growth media and environmental conditions.

The matrix effect is widely reported in literature, with emphasis on mycotoxin production, e.g., for $P$. nordicum and P. verrucosum [18,40]. The nutritional matrix effect was recently pointed out also by Coton et al. [41]; a strain of P. nordicum produced OTA and CIT in Comté cheese, while these metabolites were not detected in yeast extract with supplements medium (YES). P. crustosum was reported to produce ROQ-C on several substrates, but the highest amount was detected on cheese analogue media [42]. In the present study, P. crustosum produced more ROQ-C ( 10 times fold) than $P$. roqueforti in all the tested conditions; this is in agreement with in vitro studies, but the difference in toxin production between the two species was limited, around two- to four-fold. Further, Kokkonen et al. [42] reported a remarkable amount of CIT produced by a strain of $P$. verrucosum on bread analogue media, although not detected $(<\mathrm{LOD})$ on cheese.

All the toxins analyzed in this study were detected, except MPA, Pr-Tox, and CIT produced by P. roqueforti and P. verrucosum (below the LOD); therefore, mycotoxin synthesis is possible during grana cheese ripening. $\mathrm{T}$ range for toxin production was between 15 and $25{ }^{\circ} \mathrm{C}$, in agreement with the findings of Sànchez-Monter at al. [40]; they reported that P. verrucosum and P. nordicum produced OTA readily in the range $15-25^{\circ} \mathrm{C}$ on dry-cured meat products. On the contrary, STC was optimally 
produced by $A$. versicolor at $10-15{ }^{\circ} \mathrm{C}$; this fungus is known as mesophilic, with a minimum $\mathrm{T}$ for growth of $9{ }^{\circ} \mathrm{C}$ at $0.97 a_{\mathrm{W}}$ [43].

Both the limited $\mathrm{T}$ regimes that enabled toxin production and the anomalous behavior of $A$. versicolor justify the difficulties of transferring the predictive models obtained in vitro for mycotoxin production to real conditions on cheese. In addition, a previous study carried out on dry-cured ham considered incubation periods of $P$. nordicum on ham tassels up to 190 days, on account of the long ripening period of the product (minimum 12 months); a considerable impact of long incubation time on OTA production was detected [18]. Only in one study, regarding CIT and OTA production by $P$. verrucosum in a semi-hard French PDO cheese, longer incubation periods (42 days) compared to the 21 days of this study were tested [41]; at $20^{\circ} \mathrm{C}$ both mycotoxins were produced after seven days, but for a longer incubation period ( 35 and 42 days) OTA production was higher than CIT and after 42 days OTA concentration reached its highest point. Therefore, an increase of the incubation period could be useful to better simulate the real ripening period (months), to give fungi enough time to adapt to the matrix and optimize their metabolism on the nutritional source. Data coming from that kind of study should be suitable to test the existing models or eventually to develop new ones.

The partitioning of mycotoxins between the mycelium and their release on cheese rind varied significantly for different fungi, irrespective of incubation T. In particular, the occurrence of STC and OTA produced by A. versicolor and P. verrucosum, respectively, was the highest in cheese rind; for all the other combinations, almost all the toxins were not released on the medium. This finding is crucial in practice; in fact, the removal of fungal mycelium should guarantee a safe product, at least for most of the toxins considered. However, studies with longer incubation periods should be carried out to confirm this result. In agreement with our results, Coton at al. [41] detected on Comté cheese OTA and CIT, produced by P. verrucosum, up to $1.6 \mathrm{~cm}$ in depth, depending on the incubation time; additionally, they underlined that the highest concentration was detected when the mold was present. The rind of grana type cheeses is edible and a standard amount of rind is permitted in grated cheese; therefore, knowledge of both the ecological needs of toxin-producing fungi and the rate of mycotoxin release on the matrix are important for the prevention of consumer exposure.

On the other hand, this should also support grana cheese rind management during ripening. In fact, during ripening, cheese wheels repeatedly undergo surface clean-up brushing operations. The growing mold is therefore removed, but fungal spores are also airborne-spread, increasing their dispersal in the storehouse and providing further opportunities of growth due to the micro-damage caused on the cheese rind surface. Camardo Leggieri et al. [14], reported that P. crustosum, P. nordicum, and $P$. verrucosum had shown an optimum $\mathrm{T}$ for sporulation between 20 and $25^{\circ} \mathrm{C}$ and their sporulation continued up to $a_{w}=0.87$ ( $a_{w}=0.83$ for $P$. nordicum); therefore, they are adapted to the environmental conditions of storehouses for grana cheese ripening. A high spore concentration is expected when fungi grow on cheese rind, as confirmed by this study, with sporulation reported for all fungi from 10 days of incubation.

In conclusion, the knowledge acquired in this study confirms that the (co-)occurrence of several mycotoxin in cheese is possible. Some fungi release most of the toxins in the medium and neither $\mathrm{T}$ during ripening nor cheese $a_{w}$ can act as limiting factors; this should be considered in the grana cheese management, even if no regulation is actually in force. Further studies, following the same approach reported here, but with longer incubation periods, should be planned in the future to make results more consistent and to support mycotoxin modelling. Nevertheless, these outcomes are important and may contribute to the optimization of grana cheese management.

Supplementary Materials: The following are available online at http://www.mdpi.com/2076-2607/8/1/69/s1, Table S1: Colony diameters $(\mathrm{mm})$ and mycotoxin production $(\mathrm{ng})$ after 21 days of incubation. Partitioning levels of mycotoxin produce by the fungi on cheese rind and by fungal mycelium were provided, as well as the total amount.

Author Contributions: Conceptualization, P.B. and M.C.L.; methodology, P.B. and M.C.L.; formal analysis, A.P. and M.C.L.; data curation, M.C.L.; writing-original draft preparation, M.C.L.; writing-review and editing, P.B. and A.P. All authors have read and agreed to the published version of the manuscript. 
Funding: This research received no external funding.

Acknowledgments: The authors thank Consorzio per la tutela del Formaggio Grana Padano and Consorzio del Formaggio Parmigiano Reggiano for their support providing cheese rind blocks used in the study, however they had no role in any step of this study. The authors would like to thank Giacomo Riboldi who contributed to this study during the course of his master's thesis carried out at the Università Cattolica del Sacro Cuore (Italy).

Conflicts of Interest: The authors declare no conflict of interest.

\section{References}

1. Camardo Leggieri, M.; Decontardi, S.; Bertuzzi, T.; Pietri, A.; Battilani, P. Modeling growth and toxin production of toxigenic fungi signaled in cheese under different temperature and water activity regimes. Toxins 2017, 9, 4. [CrossRef]

2. Ministero Delle Politiche Agricole e Forestali. Available online: http://www.politicheagricole.it (accessed on 22 November 2019).

3. Ropars, J.; Cruaud, C.; Lacoste, S.; Dupont, J. A taxonomic and ecological overwiew of cheese fungi. Int. J. Food Microbiol. 2012, 155, 199-210. [CrossRef]

4. Lund, F.; Filtenborg, O.; Frisvad, J.C. Associated mycoflora of cheese. Food Microbiol. 1995, 12, $173-180$. [CrossRef]

5. Montagna, M.T.; Santacroce, M.P.; Spilotros, G.; Napoli, C.; Minervini, F.; Papa, A.; Dragoni, I. Investigation of fungal contamination in sheep and goat cheeses in southern italy. Mycopathologia 2004, 158, 245-249. [CrossRef]

6. Creppy, E.E. Update of survey, regulation and toxic effects of mycotoxins in europe. Toxicol. Lett. 2002, 127, 19-28. [CrossRef]

7. Erdogan, A.; Gurses, M.; Sert, S. Isolation of moulds capable of producing mycotoxins from blue mouldy tulum cheeses produced in turkey. Int. J. Food Microbiol. 2003, 85, 83-85. [CrossRef]

8. Dall'Asta, C.; De Dea Lindner, J.; Galaverna, G.; Dossena, A.; Neviani, E.; Marchelli, R. The occurrence of ochratoxin a in blue cheese. Food Chem. 2008, 106, 729-734. [CrossRef]

9. Fontaine, K.; Hymery, N.; Lacroix, M.Z.; Puel, S.; Puel, O.; Rigalma, K.; Gaydou, V.; Coton, E.; Mounier, J. Influence of intraspecific variability and abiotic factors on mycotoxin production in penicillium roqueforti. Int. J. Food Microbiol. 2015, 215, 187-193. [CrossRef]

10. Decontardi, S.; Mauro, A.; Lima, N.; Battilani, P. Survey of penicillia associated with italian grana cheese. Int. J. Food Microbiol. 2017, 246, 25-31. [CrossRef]

11. Kalinina, S.A.; Jagels, A.; Hickert, S.; Mauriz Marques, L.M.; Cramer, B.; Humpf, H.U. Detection of the cytotoxic penitrems a-f in cheese from the european single market by hplc-ms/ms. J. Agric. Food Chem. 2018, 66, 1264-1269. [CrossRef]

12. Decontardi, S.; Soares, C.; Lima, N.; Battilani, P. Polyphasic identification of penicillia and aspergilli isolated from italian grana cheese. Food Microbiol. 2018, 73, 137-149. [CrossRef] [PubMed]

13. Wu, F.; Mitchell, N.J. How climate change and regulations can affect the economics of mycotoxins. World Mycotoxin J. 2016, 9, 653-663. [CrossRef]

14. Camardo Leggieri, M.; Decontardi, S.; Battilani, P. Modelling the sporulation of some fungi associated with cheese, at different temperature and water activity regimes. Int. J. Food Microbiol. 2018, 278, 52-60. [CrossRef] [PubMed]

15. Battilani, P.; Pietri, A.; Giorni, P.; Formenti, S.; Bertuzzi, T.; Toscani, T.; Virgili, R.; Kozakiewicz, Z. Penicillium population in dry-cured ham manufacturing plants. J. Food Prot. 2007, 70, 975-980. [CrossRef] [PubMed]

16. Pitt, J.I. The Genus Penicillium and Its Teleomorphic States Eupenicillium and Talaromyces; Academic Press Inc.: London, UK, 1979.

17. Dallyn, H.; Fox, A. Spoilage of material of reduced water activity by xerophilic fungi. In Society of Applied Bacteriology Technical Series; Gould, G.H., Corry, J.E.L., Eds.; Academic Press: London, UK, 1980; Volume 15, pp. 129-139.

18. Battilani, P.; Formenti, S.; Toscani, T.; Virgili, R. Influence of abiotic parameters on ochratoxin a production by a $p$. Nordicum strain in dry-cured meat model systems. Food Control 2010, 21, 1739-1744. [CrossRef]

19. Analytis, S. Über die relation zwischen biologischer entwicklung und temperatur bei phytopathogenen pilzen. Phytopathol. Z. 1977, 90, 64-76. [CrossRef] 
20. Sengun, I.Y.; Yaman, D.B.; Gonul, S.A. Mycotoxins and mould contamination in cheese: A review. World Mycotoxin J. 2008, 1, 291-298. [CrossRef]

21. Biancardi, A.; Piro, R.; Galaverna, G.; Dall'Asta, C. A simple and reliable liquid chromatography-tandem mass spectrometry method for determination of ochratoxin a in hard cheese. Int. J. Food Sci. Nutr. 2013, 64, 632-640. [CrossRef]

22. Commission, E. Commission Regulation No 165/2010 of 26 February 2010 Amending Regulation (ec) No 1881/2006 Setting Maximum Levels for Certain Contaminants in Foodstuffs As Regards Aflatoxin; Official Journal of the European Union: Bruxelles, Belgium, 2010; pp. 8-12.

23. Commission, E. Commission Regulation (ec) No 1881/2006 Setting Maximum Levels for Certain Contaminants in Foodstuffs; Official Journal of the European Union: Bruxelles, Belgium, 2006; pp. 4-24.

24. Di Giuseppe, R.; Bertuzzi, T.; Rossi, F.; Rastelli, S.; Mulazzi, A.; Capraro, J.; De Curtis, A.; Iacoviello, L.; Pietri, A. Plasma ochratoxin a levels, food consumption, and risk biomarkers of a representative sample of men and women from the molise region in italy. Eur. J. Nutr. 2012, 51, 851-860. [CrossRef]

25. Galvano, F.; Pietri, A.; Bertuzzi, T.; Gagliardi, L.; Ciotti, S.; Luisi, S.; Bognanno, M.; La Fauci, L.; Iacopino, A.M.; Nigro, F.; et al. Maternal dietary habits and mycotoxin occurrence in human mature milk. Mol. Nutr. Food Res. 2008, 52, 496-501. [CrossRef]

26. Muñoz, K.; Blaszkewicz, M.; Campos, V.; Vega, M.; Degen, G.H. Exposure of infants to ochratoxin a with breast milk. Arch. Toxicol. 2014, 88, 837-846. [CrossRef] [PubMed]

27. Soto, J.B.; Ruiz, M.J.; Manyes, L.; Juan-García, A. Blood, breast milk and urine: Potential biomarkers of exposure and estimated daily intake of ochratoxin a: A review. Food Addit. Contam. 2016, 33, 313-328. [CrossRef] [PubMed]

28. Biasucci, G.; Calabrese, G.; Di Giuseppe, R.; Carrara, G.; Colombo, F.; Mandelli, B.; Maj, M.; Bertuzzi, T.; Pietri, A.; Rossi, F. The presence of ochratoxin a in cord serum and in human milk and its correspondence with maternal dietary habits. Eur. J. Nutr. 2011, 50, 211-218. [CrossRef] [PubMed]

29. Alassane-Kpembi, I.; Schatzmayr, G.; Taranu, I.; Marin, D.; Puel, O.; Oswald, I.P. Mycotoxins co-contamination: Methodological aspects and biological relevance of combined toxicity studies. Crit. Rev. Food Sci. Nutr. 2017, 57, 3489-3507. [CrossRef]

30. Grenier, B.; Oswald, I.P. Mycotoxin co-contamination of food and feed: Meta-analysis of publications describing toxicological interactions. World Mycotoxin J. 2011, 4, 285-313. [CrossRef]

31. Lee, H.J.; Ryu, D. Worldwide occurrence of mycotoxins in cereals and cereal-derived food products: Public halth perspectives of their co-occurrence. J. Agric. Food Chem. 2017, 65, 7034-7051. [CrossRef]

32. Yang, Y.; Yu, S.; Tan, Y.; Liu, N.; Wu, A. Individual and combined cytotoxic effects of co-occurring deoxynivalenol family mycotoxins on human gastric epithelial cells. Toxins 2017, 9, 96. [CrossRef]

33. Sobral, M.M.C.; Faria, M.A.; Cunha, S.C.; Ferreira, I.M. Toxicological interactions between mycotoxins from ubiquitous fungi: Impact on hepatic and intestinal human epithelial cells. Chemosphere 2018, 202, 538-548. [CrossRef]

34. McSweeney, P.L.H. (Ed.) Nutritional aspects of cheese. In Cheese Problems Solved; Woodhead Publishing: Sawston, UK, 2007; pp. 152-158.

35. Summer, A.; Formaggioni, P.; Franceschi, P.; Di Frangia, F.; Righi, F.; Malacarne, M. Cheese as functional food: The example of parmigiano reggiano and grana padano. Food Technol. Biotechnol. 2017, 55, 277-289. [CrossRef]

36. Frisvad, J.C.; Smedsgaard, J.; Larsen, T.O.; Samson, R.A. Mycotoxins, drugs and other extrolites produced by species in penicillium subgenus penicillium. Stud. Mycol. 2004, 49, 201-241.

37. Manabe, M. Fermented foods and mycotoxins. Mycotoxins 2001, 51, 25-28. [CrossRef]

38. Pardo, E.; Marín, S.; Ramos, A.J.; Sanchis, V. Ecophysiology of ochratoxigenic aspergillus ochraceus and penicillium verrucosum isolates. Predictive models for fungal spoilage prevention-A review. Food Addit. Contam. 2006, 23, 398-410. [CrossRef] [PubMed]

39. Rodriguez, A.; Capela, D.; Medina, A.; Cordoba, J.J.; Magan, N. Relationship between ecophysiological factors, growth and ochratoxin a contamination of dry-cured sausage based matrices. Int. J. Food Microbiol. 2015, 194, 71-77. [CrossRef] [PubMed] 
40. Sánchez-Montero, L.; Córdoba, J.J.; Peromingo, B.; Álvarez, M.; Núñez, F. Effects of environmental conditions and substrate on growth and ochratoxin a production by penicillium verrucosum and penicillium nordicum: Relative risk assessment of ota in dry-cured meat products. Food Res. Int. 2019, 121, 604-611. [CrossRef] [PubMed]

41. Coton, M.; Auffret, A.; Poirier, E.; Debaets, S.; Coton, E.; Dantigny, P. Production and migration of ochratoxin a and citrinin in comté cheese by an isolate of penicillium verrucosum selected among penicillium spp. Mycotoxin producers in yes medium. Food Microbiol. 2019, 82, 551-559. [CrossRef]

42. Kokkonen, M.; Jestoi, M.; Rizzo, A. The effect of substrate on mycotoxin production of selected penicillium strains. Int. J. Food Microbiol. 2005, 99, 207-214. [CrossRef]

43. Hocking, A.D. Aspergillus and related teleomorphs. In Food Spoilage Microorganisms; Woodhead Publishing Limited: Abington, UK, 2006; pp. 451-487.

(C) 2020 by the authors. Licensee MDPI, Basel, Switzerland. This article is an open access article distributed under the terms and conditions of the Creative Commons Attribution (CC BY) license (http://creativecommons.org/licenses/by/4.0/). 